\title{
Caracterização magnetométrica da região limítrofe cráton e faixa móvel: exemplo da borda ocidental do cráton São Francisco
}

\author{
Caio Alencar Matos, Paulo Henrique Amorim Dias, Luiz Gustavo Rodrigues Pinto, Marcelo de Souza Marinho, \\ Marcus Paulo Sotero e Marco Antonio Couto Jr., CPRM - Serviço Geológico do Brasil
}

Copyright 2016, SBGf - Sociedade Brasileira de Geofísica

Este texto foi preparado para a apresentação no VII Simpósio Brasileiro de Geofísica Ouro Preto, 25 a 27 de outubro de 2016. Seu conteúdo foi revisado pelo Comitê Técnico do VII SimBGf, mas não necessariamente representa a opinião da SBGf ou de seus associados. É proibida a reprodução total ou parcial deste material para propósitos comerciais sem prévia autorização da SBGf.

\begin{abstract}
This paper presents the direct and inverse modeling of two airborne magnetic data profiles in South-Central part of Brasilia Belt, between the cratonic and external domains. The profiles have E-W direction and are localized between Paracatu an João Pinheiro cities. One of them follows the seismic line of 240-292 segment (Paracatu line) and the other one passes by the Morro Agudo deposit. The objectives of the profile modeling were to assist the interpretation of some seismic features observed in the Paracatu line, estimate the geometry and depth of the crystalline basement and to model the shallow magnetic bodies. The magnetic models showed good consistency with the results of seismic line and provide important information about the crystalline basement and the shallow magnetic sources. Although gravimetric data were not used in the modeling process, its analysis suggests a negative value of mass density contrast between the crystalline basement and sediments.
\end{abstract}

\section{Introdução}

A faixa Brasília compõe juntamente com as faixas Araguaia e Paraguai a Província Tocantins, (Fuck et al., 1993). Trata-se de um cinturão orogênico formado no ciclo Brasiliano decorrente da colisão dos paleocontinentes São Francisco, Amazonas e Paranapanema (Valeriano et al. 2004; Pimentel et al., 2011). Essa faixa pode ser dividida em três compartimentos tectônicos, Zona interna, Externa e Domínio Cratônico.

A Zona Externa é composta por uma sequência de margem passiva estenianos, abrangendo os grupos Paranoá, Vazante e Canastra e pela sequência sedimentar de bacias de antepaís neoproterozoica, do Grupo lbiá (Rodrigues, 2008) (Figura 1). Esse domínio está posicionado sobre o domínio Cratônico através de falhas contracionais e destaca-se em termos metalogenéticos por abarcar os distritos zincíferos e plumbo zincíferos de Vazante e Morro Agudo, respectivamente.

O Domínio Cratônico é composto pelas sequências sedimentares de bacias de antepaís, representadas pelo grupo Bambuí (Coelho et al. 2008).
No presente trabalho foi realizada a modelagem de dois perfis magnetométricos na região limite entre a Zona Externa e domínio Cratônico.

Os perfis realizados no trabalho têm como intuito auxiliar na interpretação do comportamento do embasamento cristalino e da discriminação de corpos magnéticos rasos. A modelagem do topo do embasamento cristalino pode ajudar no entendimento tectônico da região e na possível separação em profundidade da Zona Externa e do Domínio Cratônico.

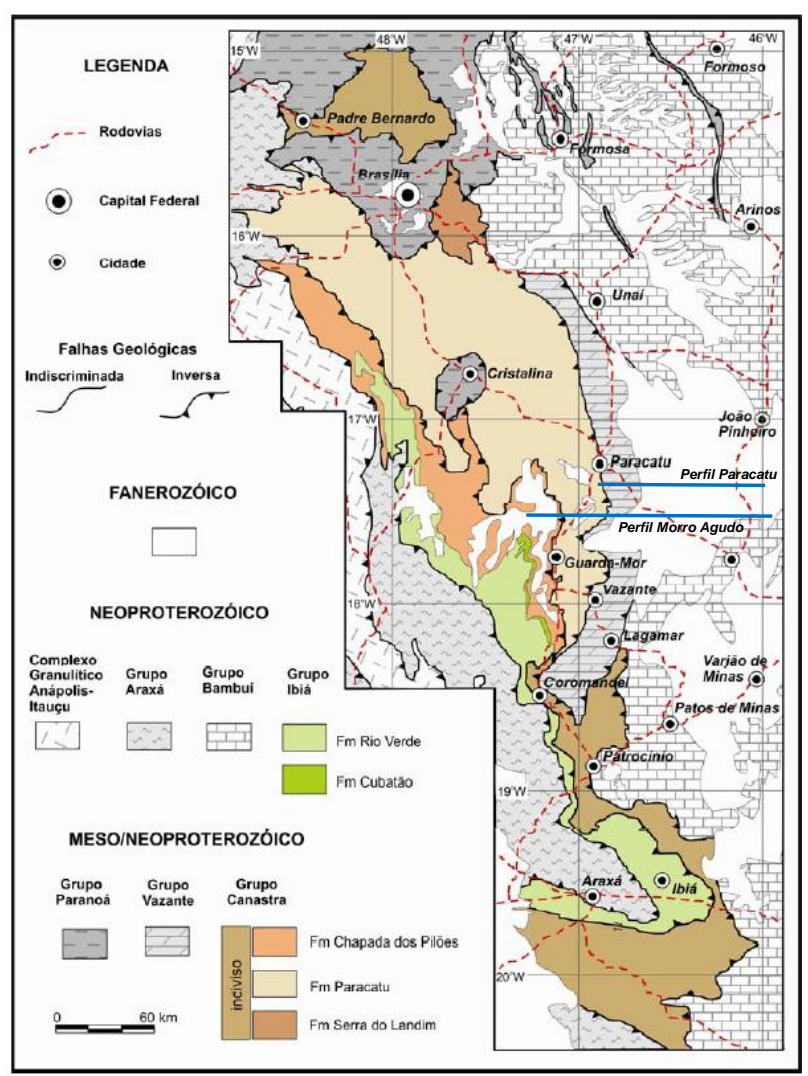

Figura 1. Mapa da porção sudoeste da Faixa Brasília. Os perfis magnetométrico modelados estão representados pelas linhas azuis.

O estudo analisa dados de gravimetria, porém não foi realizada nenhuma modelagem com este método.

O primeiro perfil modelado encontra-se sobre a linha sísmica de Paracatu, o segundo, um modelo regional paralelo à sísmica de Paracatu, que passa sobre a mina de Morro Agudo. A localização dos perfis está representada nas Figura 1 e Figura 2. 


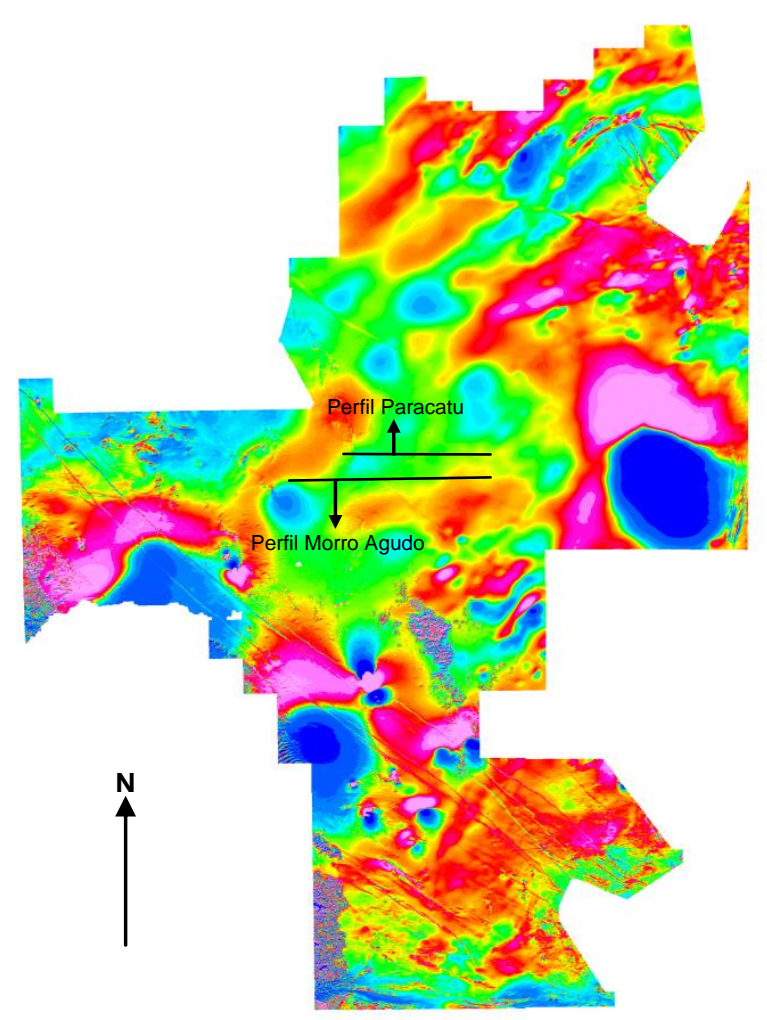

Figura 2. Mapa magnetométrico reduzido ao polo. Em preto estão representados os dois perfis modelados, sísmica de Paracatu, acima, e Morro Agudo, abaixo.

\section{Metodologia}

A linha sísmica (Figura 3) utilizada neste trabalho corresponde ao segmento 0240-0292 (linha sísmica de Paracatu), migrada pelo tempo e obtida através do Banco de Dados de Exploração e Produção (BDEP) da Agência Nacional do Petróleo (ANP) através do convênio com o Serviço Geológico do Brasil - CPRM. Não foi realizado nenhum processamento a mais sobre esta linha. Para visualizá-la, foi utilizado o software Opendtect 4.2 , com o pacote da versão gratuita.

Os dados de magnetometria utilizados são do levantamento Minas Gerais, Área 01 - Paracatu-Vazante, contratado pela CODEMIG e CPRM e do levantamento ANP, contratado pela ANP. A área 01 é considerada um levantamento de detalhe com as linhas de voo espaçadas de $250 \mathrm{~m}$. A direção do voo, na área utilizada, foi SW-NE. Os dados foram processados no software Oasis Montaj da Geosoft, onde foi feita a redução ao polo e retirado os perfis do próprio grid.

Para executar a modelagem direta foi utilizado o software GMSYS da Geosoft. Foram utilizadas ferramentas de inversão, do próprio software GMSYS, para estimar a susceptibilidade magnética do embasamento cristalino. $\mathrm{Na}$ modelagem da magnetometria, a linha sísmica de Paracatu foi utilizada como modelo de entrada. Para isso, foram traçados os horizontes na linha sísmica. Como a linha está migrada pelo tempo, foi utilizado uma velocidade sísmica estimada de $6 \mathrm{~km} / \mathrm{s}$ apenas para ter uma profundidade de entrada no modelo.

Os dados de gravimetria terrestre foram cedidos pelo Banco Nacional de Dados Gravimétricos (BNDG) da Agência Nacional do Petróleo (ANP), já com a anomalia Bouguer simples calculada. Ao longo da linha sísmica as estações estão espaçadas de forma irregular, com um espaçamento em torno de $8 \mathrm{~km}$.

\section{Resultados}

A Figura 3 mostra a linha sísmica de Paracatu interpretada. A parte oeste da linha sísmica tem uma região, marcada em verde, com ausência de refletores. Em amarelo estão possíveis falhas normais. Em preto estão marcados os limites de unidades sedimentares. A profundidade do embasamento cristalino, representado em vermelho, varia de 1,7 a 2,3 s e representa uma profundidade estimada entre $5 \mathrm{~km}$ e $7 \mathrm{~km}$. A linha vermelha mostra que o embasamento está mais raso a leste em relação a oeste.

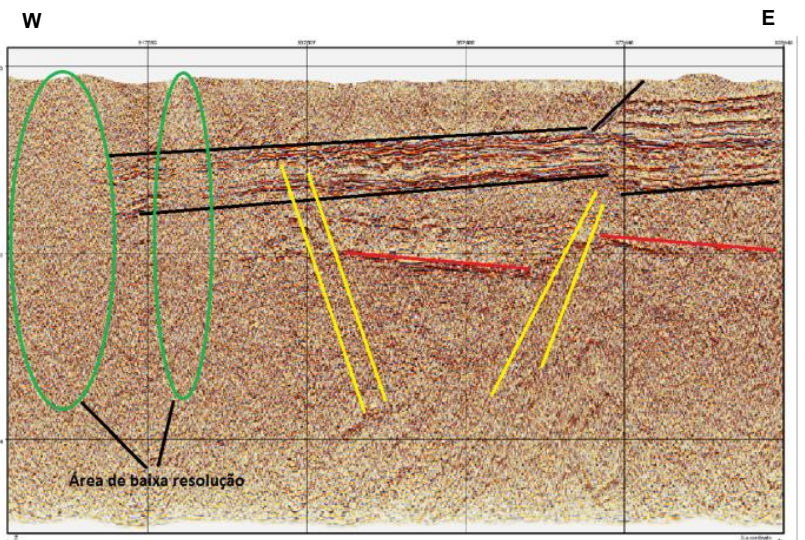

Figura 3. Linha sísmica de Paracatu, sentido oeste-leste, interpretada. Em amarelo estão possíveis falhas no embasamento, em preto as principais unidades sedimentares e em vermelho o topo do embasamento cristalino. A região verde é uma área com poucos refletores.

A Figura 4 mostra o modelo magnetométrico direto feito sobre a linha sísmica de Paracatu. Na janela superior está representada a intensidade do campo magnético reduzido ao polo, pela linha pontilhada, e a intensidade do campo magnético calculado a partir do modelo, pela linha contínua. A janela inferior mostra o modelo gerado e a respectiva susceptibilidade magnética de cada unidade. Os pacotes sedimentares pouco influenciam na resposta magnética devido a sua baixa susceptibilidade magnética, portanto, a principal resposta, da componente regional do modelo, será, em grande parte, devido ao embasamento cristalino. Por esta razão a susceptibilidade dos sedimentos, utilizadas nos modelos, variou de 0,0001 SI a 0,0002 SI. 
A susceptibilidade magnética do embasamento, calculada a partir da inversão, é de 0,02 SI. Embora a magnetometria não seja um método adequado para estimar a base de corpos magnéticos, alguns destes corpos estavam em regiões coincidentes com falhas modeladas no embasamento cristalino, o que pode indicar que este corpo tenha origem deste embasamento. $\mathrm{Na}$ parte oeste do perfil foram modelados diversos corpos magnéticos rasos, os corpos verticais foram modelados com susceptibilidade magnética de $0,02 \mathrm{SI}$ e os corpos sub-horizontais $0,005 \mathrm{SI}$. A presença desses corpos pode explicar as áreas de baixa resolução na linha sísmica (Figura 3). Esses corpos são em grande parte verticalizados e podem representar intrusões de diques máficos, comuns na região de trabalho.

w

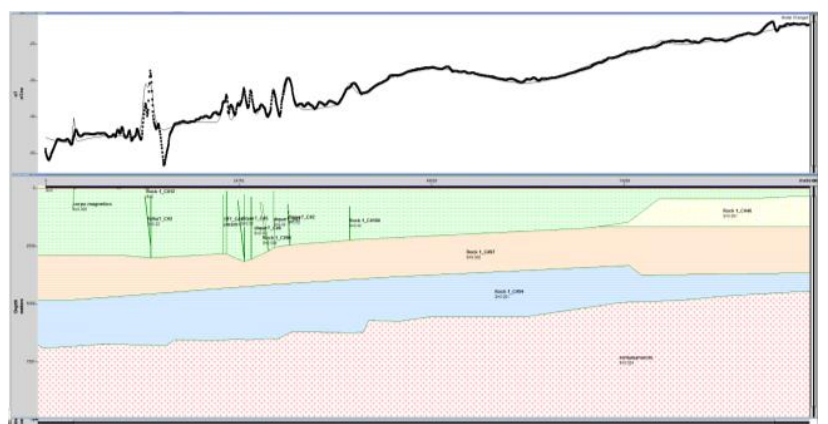

Figura 4. Modelo magnetométrico da linha sísmica de Paracatu. Os pontos na janela superior indicam as medidas do campo reduzido ao polo, a linha contínua indica o campo magnético calculado a partir do modelo. Na janela de baixo está o modelo magnetométrico.

A análise do perfil gravimétrico de anomalia Bouguer (Figura 5) sobre a linha sísmica de Paracatu mostra que a anomalia gravimétrica tem um comportamento inverso à magnetometria. Assim, o baixo gravimétrico presente na parte leste do perfil compreende um alto magnetométrico, comportando-se de modo inverso na parte oeste. Considerando a elevação do embasamento baseado na interpretação da linha sísmica e na modelagem magnetométrica, era esperado um comportamento distinto para a gravimetria. Uma hipótese é que o embasamento cristalino nessa área possui uma densidade menor do que o pacote sedimentar que está acima dele. Uma possível explicação para o fato seria a presença de espessos pacotes dolomíticos presentes na área, cuja densidade chegam a valores próximos de $3 \mathrm{~g} / \mathrm{cm}^{3} \quad$ (McGladrey, 2014). Entretanto estudos petrofísicos e gravimétricos de maior detalhe são essenciais para compreender esse comportamento.

Ao considerar o contraste de densidade, do embasamento cristalino, negativo, o extremo leste do perfil apresenta uma incoerência entre 0 modelo magnetométrico e a anomalia Bouguer. Enquanto a magnetometria indica um alto no embasamento, a anomalia Bouguer indica um possível baixo. Este baixo do embasamento não pode ser descartado, dado que o extremo leste da linha sísmica não tem um forte refletor que defina bem o topo do embasamento e, como o modelo magnetométrico foi feito sobre uma anomalia reduzida ao polo, esta pode apresentar problemas de borda.

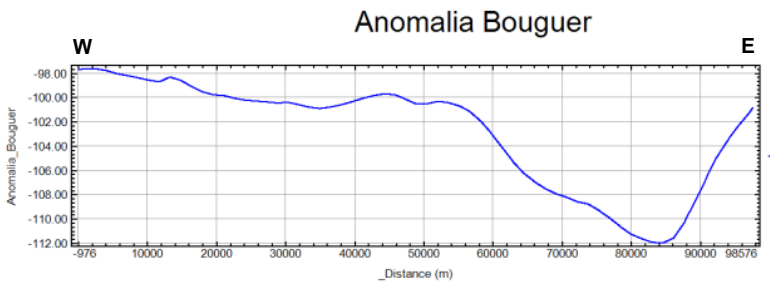

Figura 5. Anomalia Bouguer sobre o perfil da linha sísmica de Paracatu.

O segundo perfil modelado passa sobre a mina de Morro Agudo e não possui linha sísmica de suporte (Figura 6). Este modelo também apresenta possíveis corpos magnéticos rasos. Esses corpos tem orientação que variam entre subverticalizadas a horizontalizadas, com susceptibilidade magnética de 0,02 e 0,005 SI respectivamente. Entre estes, um corpo magnético possui localização compatível com a localização da mina de Morro Agudo, marcado em vermelho na Figura 7. Esse corpo possui orientação subhorizontalizada. Até o presente momento, não foi possível estabelecer uma correlação entre a assinatura magnética e a geologia presente no depósito.

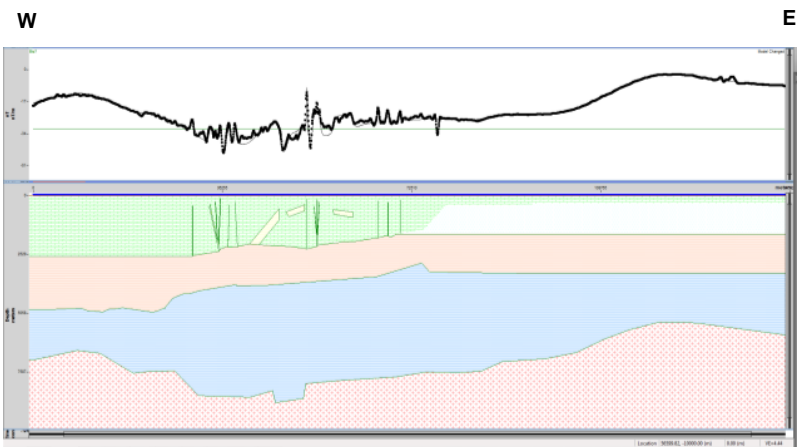

Figura 6. Modelo Morro Agudo.

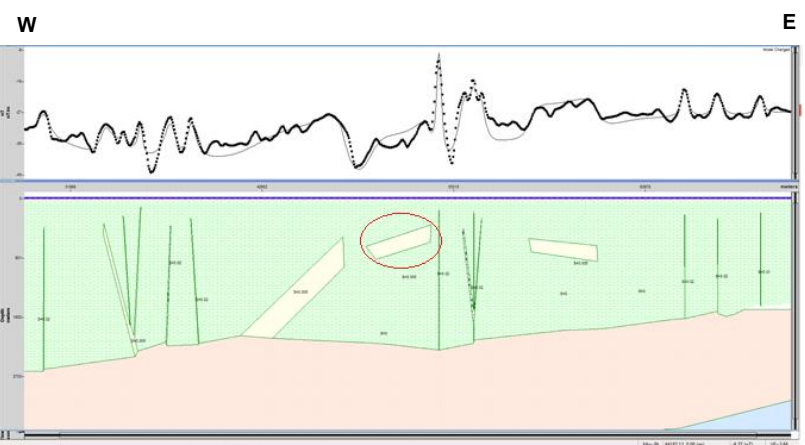

Figura 7. Detalhe do modelo de Morro Agudo. O detalhe mostra os diferentes tipos de corpos magnéticos modelados. A parte circulada de vermelho é uma região compatível com a localização em planta da mina de Morro Agudo. 


\section{Discussão e Conclusões}

No âmbito regional, o modelo magnetométrico realizado entre Paracatu e João Pinheiro se mostrou coerente com a interpretação da linha sísmica de Paracatu. Para confirmação desse modelo, recomenda-se uma aquisição terrestre de gravimetria de maior detalhe, além de estudos petrofísicos da área. A interpretação da anomalia Bouguer indica que no extremo leste possa haver uma descida do embasamento, esta decida não é incompatível com a sísmica e sua incompatibilidade com a magnetometria pode ser explicada como um possível efeito de borda da redução ao polo.

Os corpos verticais indicados pela magnetometria, possivelmente, tratam-se de diques básicos subverticalizados e dessa forma explicariam as regiões de baixa resolução na parte oeste da linha sísmica, dado o alto contraste de impedância acústica desses corpos em relação ao entorno. Uma aquisição terrestre de gravimetria de detalhe poderia ajudar a confirmar a presença desses corpos verticais. Recomenda-se também avaliar as assinaturas desses corpos na gamaespectrometria e, caso haja relação, sua checagem em campo.

No modelo de Morro Agudo foi possível interpretar o topo do embasamento cristalino, que varia em profundidade de $5 \mathrm{~km}$, a leste, se aproxima de $8 \mathrm{~km}$, na região central, e volta a subir até cerca de $6 \mathrm{~km}$ a oeste. Foram interpretados também corpos magnéticos cuja orientação varia entre vertical a sub-horizontal. De acordo com a modelagem, os corpos subverticalizados apresentam suceptibilidade magnética inferiores aos inclinados. A resposta do perfil sobre a mina sugere um corpo menos magnético que os corpos verticais, com um mergulho para oeste e não aflorante. Como a susceptibilidade foi escolhida de forma arbitrária, é recomendado um estudo pretrofísico para que seja utilizado um valor mais próximo do real e o modelo do corpo seja refeito. Na porção oeste e leste da mina existem mais corpos com assinaturas magnetométricas similares. É indicado que sejam feitos mais estudos visando avaliar a o que se associa a resposta magnética deste corpos.

A geometria do embasamento cristalino obtida através do tratamento conjunto dos dados geofísicos sugere que a zona de cavalgamento que define o limite entre a Zona Externa e o domínio Cratônico não possui expressão em profundidade. Dessa forma, tal deformação teria um caráter epidérmico, limitado a porções superiores dos pacotes sedimentares. Entretanto, é possível que estruturas pretéritas, tais como as falhas normais observadas na linha sísmica de Paracatu (Figura 3), tiveram influência na nucleação das estruturas epidérmicas.

A utilização da modelagem magnética associada à interpretação sísmica permitiu uma maior confiabilidade para as interpretações em áreas cujos dados sísmicos não estão disponíveis. Os resultados apresentados ajudam a ter uma visão do arcabouço estrutural do embasamento cristalino na região. Porém, é necessária a realização de levantamentos gravimétricos de detalhe, além de um número maior de perfis de magnetometria modelados de maneira a obter um maior grau de refinamento do arcabouço da região. A realização de trabalhos de campo é necessária para tentar identificar a natureza dos diversos corpos rasos presentes nos modelos.

\section{Agradecimentos}

Agradeço a todos que me ajudaram neste trabalho e à CPRM, ANP e CODEMIG por disponibilizar os aerolevantamentos magnetométricos.

\section{Referências}

Fuck, R. A.; Jardim de Sá, E. F.; Pimentel, M. M.; Dardenne, M. A.; Pedrosa Soares, A. C. 1993. As faixas de dobramentos marginais do Cráton do São Francisco: síntese dos conhecimentos. In: Dominguez, J. M. L. \& Misi, A. - O Cráton do São Francisco: trabalhos apresentados na reunião preparatória do II Simpósio sobre o Cráton do São Francisco. SBG, SGM, CNPq, Salvador, p. $161-186$.

Valeriano, C. M.; Pimentel, M. M.; Heilbron, M.; Almeida, J. C. H.; Trouw, R. A. J. 2008. Tectonic evolution of the Brasília Belt, Central Brazil, and early assembly of Gondwana. Geological Society, London, Special Publications. 284:197-210.

Pimentel, M. M.; Rodrigues, J. B.; Della Giustina, M. E. S; Junges, S; Matteini, M. e Armstrong, R. 2011. The tectonic evolution of the Neoproterozoic Brasília Belt, central Brazil, based on SHRIMP and LA-ICPMS UePb sedimentary provenance data: A review. Journal of South American Earth Sciences, 31:345 a 357.

Rodrigues, J. B. 2008. Proveniência de sedimentos dos grupos Canastra, Ibiá, Vazante e Bambuí - Um estudo de zircões detríticos e Idades Modelo Sm-Nd. Tese de Doutorado. Universidade de Brasília. 128p.

Coelho, J.C.C.; Martins-Neto, M.A.; Marinho, M.S. 2008. Estilos estruturais e evolução tectônica da porção mineira da Bacia Proterozóica do São Francisco. Revista Brasileira Geociências. 38 (2-suplemento), p. 149 e 165.

Coelho, J.C.C. 2007. Estilos estruturais e evolução tectônica da borda oeste da baica do São Francisco, com base na integração de dados de superfície, subsuperfície, litogeoquímica e isótopos. Dissertação de Mestrado, Departamento de Geologia da Escola de Minas, Universidade Federal de Ouro Preto - UFOP, Ouro Preto. 115 p.

McGladrey, A. 2014. The integration of physical rock properties, mineralogy and geochemistry for the exploration of large hypogene zinc silicate deposits: a case study of the vazante zinc deposits, minas gerais, Brazil. Dissertação de mestrado Queen's University, Ontario, Canada. 166 p. 